\title{
Decisões curriculares e participação
}

*Pedagoga com pós-graduação em Supervisão e Currículo na PUC. Diretora do Ensino de $1^{\circ}$ e $2^{\circ}$ Graus da Secretaria de Educação da Rede Municipal de Ensino de São Paulo, na gestão do prof. Paulo Freire e atual colaboradora do Cenpec

E-mail:meyri@cenpec.org.br

**Pedagoga. Coordenadora do Programa de Formação para Professores de $4^{\underline{a}}$ e $5^{\underline{a}}$ séries da Rede Municipal de Ensino, na gestão Paulo Freire e atual colaboradora do Cenpec

E-mail:zeze@cenpec.org.br
Resumo: A escola cumpre sua função social por meio do currículo, compreendido como o conjunto de conhecimentos e experiências de aprendizagens, oferecido aos estudantes, que abrange os conteúdos a serem contemplados mais a forma de desenvolvê-los. 0 artigo aborda os espaços de participação possíveis da sociedade organizada, particularmente daqueles envolvidos com a educação pública, na tomada de decisões curriculares, exteriores à escola, ou as que ocorrem no seu interior. Aponta duas lógicas de construção do currículo seguidas pelos sistemas de ensino: a clássica, mais frequente, que se movimenta do centro para as bases, e a participativa, no sentido oposto, das bases para o centro. Ressalta a importância política e pedagógica da opção pela segunda lógica, particularmente neste momento da história brasileira, em que a educação pública de qualidade está na pauta, implicando colocar o currículo em debate.

Palavras-chave: Currículo. Decisões curriculares. Currículo e participação. 
"Discutir sobre o que acontece, o que pode acontecer em salas de aula não é o mesmo que conversar sobre o tempo. Essas discussões são fundamentalmente sobre as esperanças, os sonhos, os temores e as realidades - sobre as próprias vidas - de milhões de crianças, pais e professores. Se essa tarefa não merecer a aplicação de nossos melhores esforços intelectuais e práticos - nenhuma outra merecerá."

Dentre as instituições sociais que têm a responsabilidade pela educação das novas gerações, a escola tem um papel específico: trabalhar com o ensino e a aprendizagem dos conhecimentos sistematizados da cultura letrada, para que as novas gerações dominem as linguagens e os códigos que circulam nos diferentes grupos sociais que compõem a sociedade e, assim, consigam situarse no mundo. Nesse processo, tanto se desenvolvem atitudes de conformação aos valores e normas socialmente aceitos, como atitudes de questionamento e de criação de novas respostas aos problemas que se colocam na realidade cotidiana, o que contribui para construir a identidade dos estudantes.

À escola cabe não só desenvolver as aprendizagens da tradição como faz a família, mas, também, ampliar as relações e os conhecimentos dos alunos, de forma que desenvolvam novas visões de mundo e que dialoguem com as existentes, instalando desafios ao pensamento, para que conquistem patamares mais complexos de compreensão da realidade. As aprendizagens desenvolvidas pela escola dizem respeito a conhecimentos, habilidades e valores, ou seja, formas de pensar e atuar na sociedade.

Sabemos que tais aprendizagens não são espontâneas, têm de ser intencionalmente planejadas pela escola que as concretiza por meio do currículo, entendido como o conjunto de conhecimentos e experiências de aprendizagem, oferecidos aos estudantes, que abrangem os conteúdos a ser contemplados e mais as formas de desenvolvê-los no processo de ensinoaprendizagem.

Currículo, portanto, diz sempre respeito à seleção de conteúdos (o quê?) e às formas de se efetivar a aprendizagem desses conteúdos (como?). Ele é sempre resultante de uma seleção feita entre os conteúdos culturais socialmente disponíveis na sociedade, num dado momento histórico, e de uma escolha de procedimentos pedagógicos, para que esses conteúdos sejam apropriados em sala de aula.

Diz-se que o currículo é um campo de disputas, pois tais escolhas são feitas tendo em vista o que se deseja valorizar, priorizar, dar relevância, no processo de ensino-aprendizagem. Essas escolhas não são de natureza técnica, uma vez que são norteadas por valores assumidos em relação ao que se deseja 
para a sociedade e para a formação das novas gerações, o que confere dimensão política ao currículo.

A pergunta que se coloca, então, é: quem faz isso? Quem decide o quê e como ensinar para as novas gerações? Quem tem o poder de tomar as decisões curriculares?

\section{OS DIFERENTES NÍVEIS E ATORES DAS DECISÕES CURRICULARES}

Há vários níveis de tomada de decisões curriculares, desde os mais amplos, que dizem respeito às práticas políticas, econômicas e sociais vigentes no país, até aqueles que permeiam a sala de aula.

\section{As decisões curriculares exteriores à escola}

Em primeiro lugar, é preciso considerar que o próprio contexto econômico, social e político do país e do mundo condiciona as prioridades colocadas para as políticas públicas educacionais a ser desenvolvidas, nacional e regionalmente, apontando necessidades e encaminhamentos de acordo com os dirigentes políticos e demais forças atuantes na sociedade. Isso já direciona várias decisões que são operacionalizadas por meio do estabelecimento de diretrizes norteadoras nacionais comuns e pela legislação específica do campo educacional, que incidem sobre a concepção de conhecimento, assim como sobre as prioridades do trabalho pedagógico das redes de ensino, sobre as aprendizagens que se espera que os alunos desenvolvam e sobre a atuação docente.

Além das decisões gerais, em nível nacional, há as de nível regional, no âmbito dos estados e municípios, específicas para o atendimento das realidades locais, que também orientam as decisões curriculares das escolas. Há ainda outros fatores externos que influenciam o currículo das escolas, como as decisões administrativas sobre a organização do ensino (número de disciplinas e de aulas, por exemplo), a elaboração e distribuição de livros e materiais didáticos, a pressão de grupos organizados da sociedade para se verem representados no currículo.

Para que as decisões curriculares, nesse nível do sistema, sejam democráticas e não representem apenas o interesse de determinados grupos organizados, espera-se, então, que os programas de governo de qualquer das instâncias federal, estadual ou municipal - prevejam espaços efetivos de participação 
ampla, de diferentes segmentos sociais, para discutir o contexto nacional e internacional, as diretrizes norteadoras e as leis que orientarão as decisões curriculares, no âmbito de seus territórios, dando voz às diferentes visões e posições.

No debate sobre o que é considerado legítimo e relevante ensinar para todas as crianças e todos os jovens do país, portanto, deve participar a sociedade organizada como um todo e, particularmente, os profissionais envolvidos com a educação: as universidades, os fóruns de representação de docentes, de técnicos, de alunos e de famílias. Segundo BORGES (2010, p. 18)

Um currículo construído a partir da escuta dos que fazem a educação - professores, gestores, especialistas das universidades - e do público ao qual se destina - alunos com suas famílias e comunidade - será, certamente, um currículo mais significativo, consistente e contemporâneo.

Esta é a forma de se garantir, democraticamente, às novas gerações, o direito de apropriação de aprendizagens básicas e fundamentais para se movimentar, criticamente, no complexo mundo contemporâneo.

0 que se tem constatado, em relação às decisões curriculares, nos sistemas de ensino, é que esse processo, em geral, obedece a uma das duas lógicas: a lógica de construção de currículo, que faz o movimento do centro para as bases, e a lógica que faz o movimento inverso, ou seja, das bases para o centro. A primeira, clássica e tradicional, é sustentada pela crença no progresso, na eficácia, na racionalidade técnica e caminha do nível decisor ao executor, ou seja, da administração central às escolas. A segunda é orientada pela racionalidade emancipatória, pela crença na possibilidade de mudanças, no poder criativo das pessoas e na capacidade da escola de aprender e de elaborar suas propostas; elege a participação como eixo do processo e se movimenta das escolas para os órgãos centrais.

$\mathrm{Na}$ primeira lógica, mais frequente nos sistemas de ensino, o processo é mais rápido e o produto pode ser de boa qualidade, mas compromete a adesão dos profissionais à proposta e à sua própria implementação, ou seja, a transformação do currículo formal em currículo real, na medida em que o produto oferecido é alheio às práticas dos que fazem a educação na escola. Considerados como executores, os professores não serão desafiados a criar e a se envolver no processo formativo de seus alunos.

O processo da segunda lógica é mais demorado, mas seus ganhos são expressivos e valiosos. Demanda paciência, não a que deixa as pessoas de braços cruzados, mas aquela paciência impaciente, a que se referia Paulo Freire (1997), que impulsiona para a ação e para a avaliação não apenas de resultados, 
mas que aponta também para os ganhos e as dificuldades do processo, portanto, de natureza formativa. O espaço de autonomia pedagógica dos profissionais se torna efetivo e as propostas ganham significado e relevância. A escuta dos profissionais das escolas é de fundamental importância porque dá o legítimo protagonismo a quem faz a educação acontecer no dia a dia, compartilhando, democraticamente, decisões e responsabilidades. Isso porque os professores não podem ser tratados como meros operadores de propostas alheias.

No entanto, é preciso cuidado quando se usa o conceito participação, que pode apresentar diferentes compreensões. A mais superficial diz respeito somente ao nível da informação, quando se reúnem as pessoas apenas para comunicar as decisões curriculares já tomadas, ou mesmo para, simplesmente, referendá-las. Muitas vezes, apresenta viés manipulador, nem sempre percebido pelos participantes, podendo se tornar uma tática de convencimento em relação às políticas de determinadas administrações. Nesse caso, há uma lógica ambígua do amoldamento e da obediência. Já a participação no currículo, em nível mais profundo, implica voz e vez nas tomadas de decisão. Apresenta uma moldura democrática, com respeito aos educadores e às escolas.

Podemos citar como exemplo da segunda lógica a reorientação curricular referente ao ensino do 6ำ ao 9ํano do ensino fundamental do estado de Goiás, da qual participaram as autoras deste texto, como assessoras, numa parceria entre a Secretaria de Educação do Estado, o Centro de Estudos e Pesquisas em Educação, Cultura e Ação Comunitária (Cenpec) e a Fundação Itaú Social, no período de 2004 a 2010. Essa reorientação curricular constituiu um amplo processo participativo, que atravessou duas administrações, resultando nas Matrizes Curriculares para o Ensino Fundamental do Estado.

O diferencial dessa experiência foi a ampla participação de professores e gestores das escolas da rede como autores do currículo; o envolvimento dos docentes das universidades locais: Universidade Federal de Goiás (UFG), Universidade Estadual de Goiás (UEG) e Pontifícia Universidade Católica (PUC), como coautores e assessores do processo, em todas as áreas do conhecimento, e, por fim, particularmente, o desenvolvimento de uma metodologia participativa de construção do currículo para o sistema público de ensino, fortalecendo uma política de Estado em busca da qualidade social da educação. 
[A experiência] tinha o propósito de valorizar os saberes dos profissionais do ensino, que atuam em diferentes níveis do sistema, especialmente dos que fazem a educação no dia a dia da sala de aula. Tal opção se fundamentava na concepção de que o currículo de cada escola se modifica de fato à medida que o conjunto de educadores se mobiliza para problematizar, estudar e discutir os fatores que provocam a exclusão da escola e para construir, juntos, novos caminhos que favoreçam a inclusão social dos alunos (CHIEFFI;

O processo participativo se deu em três movimentos: diagnóstico inicial e primeiras decisões políticas; reflexões e definição de pactos: fundamentos, prioridades, eixos integradores do currículo e concepção das áreas do conhecimento; elaboração de referências curriculares e de material de apoio: pactos coletivos sobre o que ensinar e como ensinar.

O primeiro movimento foi baseado nos indicadores educacionais do sistema e nas ações já realizadas pela política da Secretaria. Tinha como propósito valorizar os saberes dos profissionais do ensino que atuam nas diferentes instâncias do sistema, especialmente dos que fazem a educação no dia a dia da sala de aula.

O segundo movimento caracterizou-se por uma mobilização intensa da rede para estudar os principais fundamentos teóricos da reorientação curricular, aprofundar o diagnóstico realizado anteriormente e pactuar importantes decisões curriculares.

O terceiro movimento gerou a produção coletiva de referenciais curriculares comuns para a rede - Matrizes Curriculares - e de materiais de apoio para sua implementação em sala de aula - Sequências Didáticas, por área do conhecimento, abordando conteúdos indicados pelos professores da rede.

Para viabilizar e concretizar a participação dos diferentes atores envolvidos na reorientação, foram realizados encontros regulares e sistemáticos de formação e ações de acompanhamento da implementação da reorientação curricular, de forma centralizada (secretaria com as equipes dos 38 órgãos regionais) e descentralizada (órgãos regionais com professores e gestores das escolas).

Como forma de dar concretude ao movimento e acesso à experiência realizada, aos consensos e pactos construídos, a Secretaria considerou importante a publicação do registro do processo de reorientação curricular, por meio da elaboração dos Cadernos Currículo em Debate, que totalizaram 31 volumes de apoio e sustentação ao trabalho técnico e docente, ao lado da formação continuada e do acompanhamento. Alguns depoimentos de envolvidos no 
processo podem ilustrar o impacto do processo participativo nas diferentes instâncias do sistema:

\begin{abstract}
A reorientação curricular está sendo muito importante para o nosso aperfeiçoamento enquanto educador. É o momento em que pensamos e repensamos nossa prática pedagógica para, então, enriquecê-la e, o melhor, ajudar a construir um currículo que esteja de acordo com a nossa realidade e a do aluno (SILVA, 2009, p. 50). 1

A equipe de SEDUC, responsável por reorientar o currículo em Goiás, escolheu um caminho bem mais longo, e por isso mais árduo, que exigiria um grande fôlego dos envolvidos $e$ muita vontade política da secretaria. O caminho escolhido foi o da participação (Rosely Vanderley, subgerente de reorientação curricular da Seduc 2004-2006). ${ }^{2}$

A reorientação curricular trouxe para a universidade um estreitamento de laços que propiciou uma visão mais ampla e concreta acerca da realidade, fora do âmbito da academia, e, nesse sentido, pôde-se discutir e propor subsídios teórico-metodológicos que melhor pudessem contribuir para a educação oferecida aos alunos das várias áreas do conhecimento. Pôde, ainda, possibilitar aos futuros professores um contato mais direto com aqueles que estão envolvidos no processo de reorientação curricular e, eventualmente, aproximá-los das realidades educacionais e das reais exigências que encontrarão ao adentrarem o campo profissional (OLIVEIRA, 2009, p. 9). ${ }^{3}$
\end{abstract}

\title{
As decisões curriculares no interior das escolas
}

Das observações anteriores não se conclui que a escola seja o único centro de decisões. Mas é preciso considerar que, se por um lado, o currículo a ser desenvolvido na escola é resultante de decisões exteriores a ela, por outro, ele também é fruto de recontextualizações que ocorrem concretamente no seu interior, o que Sacristán (2007) denomina "contexto de realização”. São transformações que ocorrem pela interpretação das orientações pedagógicas oficiais legais, pela mudança de foco e pela produção de novas composições, que se dão no espaço da escola, tanto no que se refere à programação comum do coletivo dos professores, como ao que acontece na sala de aula.

\section{Segundo Sampaio (1998, p. 13),}

[...] o currículo real, aquele que se desenvolve na escola, toma forma e corpo na prática pedagógica. $O$ currículo formal é transformado e reorganizado para adequar-se à realidade da escola, articulando as opções dos professores e as necessidades dos alunos aos valores preservados e vividos no cotidiano escolar, enfim, a todo um modo de vida da escola. Essa reorganização dos saberes a serem ensinados é também fruto de negociações, opções, decisões, que envolvem os educadores e viabilizam a proposta pedagógica nas condições reais da escola. 
Assim, a escola é o espaço de participação que pode e deve ser ocupado pelos que nela atuam. Nesse âmbito, é importante que se realize uma escuta atenta de gestores, professores, alunos, famílias e comunidade, a fim de se identificar o que é importante fazer para que todos aprendam. Esse é um momento de a escola dialogar também com os demais equipamentos e organismos sociais do território onde está situada, para ampliar as ofertas de aprendizagem aos seus alunos, estabelecendo uma rede de responsabilização educacional e otimizando o que existe no lugar, estimulando-os para que conheçam e se apropriem da cidade que habitam, se reconheçam nela, construindo novos conhecimentos e desenvolvendo habilidades e valores necessários e compativeis com a participação e a convivência democrática.

Nessa direção, vale lembrar o movimento de reorientação curricular desenvolvido na Rede Municipal de Ensino de São Paulo, na gestão do professor Paulo Freire como secretário de Educação, cuja marca também foi a participação e a construção do currículo, envolvendo diferentes grupos de interlocução: a escola, a comunidade e os especialistas das diferentes áreas do conhecimento das universidades públicas locais: Universidade de São Paulo (USP), Universidade de Campinas (Unicamp) e a Pontifícia Universidade Católica de São Paulo (PUC-SP).

Essa reorientação curricular previa o apoio ao desenvolvimento de projetos gerados pelas próprias escolas, buscando avançar na direção de sua autonomia, sempre respeitando as prioridades e princípios da política educacional. Uma iniciativa nessa direção foi a possibilidade de adesão das escolas ao Projeto da Interdisciplinaridade, no qual cada uma delas, assessorada pelas equipes pedagógicas dos Núcleos de Ação Educativa, pela Diretoria de Orientação Técnica e por assessores das universidades, construía seu próprio currículo, estabelecendo temas geradores, a partir do estudo da realidade local e de uma ampla escuta dos alunos, família e comunidade, numa nova relação entre currículo e realidade. A participação de diferentes segmentos tinha como princípio subjacente o compartilhamento de poder e de responsabilidades entre escolas e administração. Nesse processo, foram elaboradas propostas curriculares que ressignificaram os conteúdos tradicionalmente trabalhados nas escolas e buscaram outros que, na interação com eles, explicavam melhor a realidade.

A reorientação curricular apontava os caminhos e indicava as prioridades do amplo programa de formação continuada oferecido aos educadores. Organizaram-se grupos de formação para professores de educação infantil, 
alfabetizadores, diretores e coordenadores pedagógicos e professores de $4^{\underline{a}}$ e $5^{\underline{a}}$ séries do então primeiro grau (atual ensino fundamental). Vários projetos foram elaborados a partir de temas que emergiam nos currículos como: orientação sexual, direitos humanos, violência nas escolas, alfabetização de jovens e adultos e diversos conteúdos das áreas do conhecimento para que os professores se apropriassem dos avanços do conhecimento humano.

Nos dois congressos municipais de educação ocorridos naquele período manifestou-se a existência de fértil debate pedagógico nas escolas e adensamento das propostas curriculares vivenciadas em salas de aula, fatores que contribuíram para impactar positivamente os resultados educacionais da rede municipal.

A escolha desse caminho revela, entre outros aspectos, a valorização de um perfil de professor pesquisador, que reflete sobre sua prática, que cria o seu próprio trabalho e se responsabiliza por ele, em oposição ao paradigma do professor que simplesmente executa as decisões curriculares tomadas por outrem. É claro que essa escolha exige esforço político e intelectual de todos, mas oferece elementos para que o professor rompa com a equivocada prática de transmissão de conteúdos, acreditando nas possibilidades de o aluno ser sujeito de sua aprendizagem, pelo próprio fato de ele mesmo estar sendo sujeito da sua própria prática.

Para que processos como esse ou outros que envolvam decisões curriculares na escola ocorram com clareza e o devido rigor intelectual, é importante que haja estudos, reflexões coletivas e debates entre os profissionais sobre a realidade socioeconômica e cultural, sobre a escuta realizada com os diferentes segmentos da comunidade escolar, sobre os conhecimentos mais relevantes das diferentes áreas e sobre os princípios que a escola considera importante não abrir mão. É importante ressaltar que todos esses elementos devem ser considerados sempre na relação com as diretrizes gerais postas pelo sistema, entrecruzando processos, agentes e âmbitos diversos.

Quanto maior clareza em relação ao quadro sociopolítico e econômico no qual se inserem as diretrizes e orientações gerais, mais elementos se têm para compreender as orientações, apontar possiveis discordâncias, efetuar adaptações e apresentar sugestões bem fundamentadas, propiciando o vislumbre de saídas e soluções para os problemas locais. Trata-se de nutrir a melhor participação de professores e demais agentes, na elaboração do currículo, tornando possivel discutir e projetar com lucidez e alguma dose de autonomia, face às determinações gerais (SAMPAIO; GALLIAN, 2013, p. 181). 
Parodiando o gato de Alice no país das maravilhas, de Lewis Carroll, para se saber por onde caminhar, antes é preciso saber aonde se quer ir. Assim, antes de se definir o currículo, na instância da escola, é preciso definir qual é o projeto da escola, ou seja, aonde a escola quer chegar com seu trabalho, que sujeitos ela pretende formar, considerando o contexto sociocultural e econômico em que está inserida, o perfil das famílias dos alunos que a frequentam e dos professores que ali trabalham.

É só a partir daí que ela poderá definir, com coerência, o conjunto de aprendizagens de natureza cognitiva, afetiva e social que desenvolverá com seus alunos e como irá desenvolvê-las. Dependendo da visão de educação que assume, a escola irá priorizar, ou seja, centralizar o trabalho na transmissão dos conteúdos na autoridade do professor, na ordem ou na disciplina ou, então, nas necessidades e interesses dos alunos, em seu crescimento, na ampliação de sua visão de mundo.

Da mesma forma, o conhecimento veiculado pelas disciplinas também é uma escolha. Sabe-se que, por seu caráter social e histórico, o conhecimento não é neutro. Assim, o professor pode escolher dar mais ênfase a alguns fenômenos da ciência e menos a outros, ou dar a voz a alguns grupos sociais e não a outros, dependendo do que considera importante. Por exemplo: ao optar pelo ensino dos produtos das ciências naturais ou das datas e personagens históricos nas ciências sociais, não estará estimulando a investigação, o levantamento de várias hipóteses para o mesmo fenômeno natural, nem considerando as várias versões dos diferentes grupos sociais que viveram a mesma realidade, numa determinada época histórica. 0 que é mais coerente com o projeto da escola? Dependendo da visão de mundo que se decidiu desenvolver com os alunos, será escolhido um caminho e não outro. De qualquer forma, essas opções se darão dentro de parâmetros, uma vez que as escolas fazem parte do conjunto maior do sistema de ensino, que deve garantir aprendizagens básicas a todos os estudantes do país. Ainda assim, à luz das mesmas diretrizes amplas e gerais, o currículo de uma escola nunca será igual ao de outra, pois assume a feição das relações que se estabelecem no seu interior, entre os alunos, entre eles e os professores e entre seu repertório cultural e o conhecimento sistematizado.

Essas e outras questões, ao serem explicitadas e discutidas pelo coletivo dos profissionais da escola, favorecem a realização das intenções educativas 
declaradas pelos educadores no projeto da escola. Impede-se, assim, que prevaleça, na prática, o currículo oculto, aquele que se ensina sem a intenção explícita de ensinar, mas que está muito vivo nas regras, no modo de proceder, nas atitudes e encaminhamentos dos adultos, servindo apenas para disciplinar e organizar os alunos, disseminando valores e atitudes muitas vezes incoerentes com os objetivos formativos defendidos pelos educadores.

\section{CURRÍCULO E FORMAÇÃO CONTINUADA DE PROFESSORES}

Podemos dizer que reorientação curricular e formação continuada de educadores são duas faces da mesma moeda, na medida em que os dois processos se retroalimentam. As discussões curriculares qualificam técnicos, gestores e docentes do sistema para a concretização das inovações propostas e essas, na prática da sala de aula, produzem informações e conhecimentos importantes para o aperfeiçoamento da proposta curricular. Por isso, as secretarias de educação e as escolas precisam elaborar e desenvolver programas de formação, nos quais as discussões curriculares sejam matériaprima. É preciso qualificar a ação desses educadores, responsáveis pela concretização das inovações propostas por meio de estudos, de discussões e da elaboração de planos de trabalho integrados para cada campo de atuação.

A formação dos profissionais da educação, nessa perspectiva, não pode parar nunca, até porque os currículos não são e não devem ser considerados como definitivos. Fazer e reorientar currículo são ações que sempre se farão necessárias, em função das contínuas transformações das sociedades, das pessoas e do conhecimento. Por isso, as discussões e decisões curriculares devem ser constantes na política educacional, independentemente dos tempos dos governos que se sucedem.

\footnotetext{
A necessidade de reorientação se coloca porque sempre é preciso reolhar essas decisões e produções. A reorientação curricular não termina com as gestões públicas. Os registros de reorientação curricular precisam funcionar como hipóteses para que vejamos como funcionam, que identidade e legitimidade têm, o que é preciso rever em relação a estes necessários momentos de síntese. A construção do currículo e a reorientação é uma hipótese e ela precisa ser acompanhada, observada, registrada, olhada em termos de seus resultados ali, na escola, na avaliação do processo ensino-aprendizagem (SAUL, 2010, p. 37).
}

Não se pode perder de vista que o principal objetivo de uma reorientação curricular é a garantia do direito de aprender das crianças e jovens. 0 trabalho de reorientação curricular de um sistema de ensino é um movimento técnico, sem dúvida, mas é, sobretudo, um movimento político, no sentido de 
aproximar os conteúdos da escola da sua função social e torná-los elementos constitutivos da garantia e da efetividade do direito à educação.

\section{CONSIDERAÇÕES FINAIS}

A educação nunca foi tão debatida pela sociedade brasileira como está sendo hoje. Ela sempre foi central para os educadores, mas atualmente essa preocupação se estende a muitos outros segmentos da sociedade, como economistas, empresários, mídia e organizações da sociedade civil.

Uma das principais razões para a discussão mais ampla da educação, no Brasil de hoje, é a vigência do Estado democrático de Direito, como também as condições econômicas e sociais de pleno emprego, gerando demandas da sociedade e das famílias por uma escola pública de qualidade, que atenda às necessidades da sociedade de produzir profissionais em número e competência necessários ao desenvolvimento do país, assim como aos anseios dos sujeitos, que depositam na educação perspectivas de realização pessoal e de mobilidade social. Como discutir qualidade de educação implica discutir, necessariamente, currículo, este passa a ter uma condição de centralidade no debate.

Essa centralidade tem emergido também de propostas recentemente implementadas pela política educacional do governo federal, no que tange à estrutura e funcionamento do ensino básico, na perspectiva da melhoria da qualidade do ensino. Podemos citar como exemplos a ampliação do ensino fundamental para nove anos e a ampliação do tempo de permanência dos estudantes na escola. Esses fatos, dentre outros, têm apontado para a necessidade urgente de se discutirem propostas curriculares que realmente impactem a qualidade da aprendizagem e concretizem a intenção de melhorar a educação pública brasileira.

Outra razão importante para a discussão curricular são as fortes pressões exercidas pelos vários sistemas nacionais e internacionais de avaliação da qualidade da educação, como o Saeb ${ }^{4}$ e o Pisa ${ }^{5}$, por exemplo, que geram

O Sistema Nacional de Avaliação da Educação Básica (Saeb), implantado em 1990, é coordenado pelo Instituto Nacional de Estudos e Pesquisas Educacionais (Inep) e conta com a participação e o apoio das secretarias estaduais e municipais de educação das 27 Unidades da Federação.

5 O Programa Internacional de Avaliação de Alunos (em inglês: Programme for International Student Assessment - Pisa) é uma rede mundial de avaliação de desempenho escolar, realizado pela primeira vez em 2000 e repetido a cada três anos. É coordenado pela Organização para a Cooperação e Desenvolvimento Econômico (OCDE), tendo em vista melhorar as políticas e resultados educacionais. 
uma demanda politicamente organizada em direção às tomadas de decisões curriculares. Podemos dizer que "estamos vivendo sob a égide de um Estado avaliador, em que tudo se orienta por essa lógica” (SAUL, 2010, p. 37).

Numa inversão da função social da escola, a preocupação passa a ser predominantemente com os resultados e, assim, os conteúdos trabalhados nas escolas descolam-se dos propósitos de ensino e passam a ser mecanicamente desenvolvidos para se obter sucesso nas provas. São, portanto, os indicadores das avaliações que passam a definir o currículo. Em decorrência disso, outro grave fato acontece: a comercialização, nos municípios brasileiros, de sistemas apostilados de ensino, com base na mesma lógica de resultados, os quais também têm se tornado definidores de currículo, além de um nicho privilegiado de mercado.

Ao lado desse conjunto de fatores, tem havido um movimento de educadores para que o Ministério da Educação reveja a base curricular comum nacional, prevista na Lei de Diretrizes e Bases e nas Diretrizes Curriculares Nacionais, para todas as escolas brasileiras. A argumentação para essa pressão é que os Parâmetros Curriculares Nacionais precisam ser revistos, pois são muito amplos e não deixam claro para alunos, pais, educadores e sociedade, em geral, o que tem de ser ensinado e o que tem de ser aprendido.

Estamos, assim, num momento importante de tomada de decisões sobre o rumo do ensino nas escolas brasileiras, as quais não podem ficar sob a responsabilidade de alguns poucos. É hora de uma chamada pública e organizada para ouvir o que a sociedade tem a dizer. Essa é a única forma de impedir que apenas algumas vozes sejam definidoras do currículo e que o produto final represente os interesses de uma minoria. Ressaltamos a importância da participação dos professores e gestores das escolas no debate, assim como de representantes das diferentes instâncias dos sistemas públicos de ensino, pois são eles que fazem a educação no dia a dia. A ruptura entre o fazer e o pensar desqualifica a prática dos sujeitos e os aliena. Reiteramos, assim, que o processo participativo é o que dá legitimidade e concretude ao currículo formal, aumentando as possibilidades de transformálo em currículo real, aquele que de fato acontece na sala de aula.

Cabe destacar, ainda, a importante e necessária participação da Universidade na tomada das decisões curriculares, uma vez que ela reúne as recentes produções de pesquisa no campo do currículo e também nas diferentes áreas do conhecimento. Sua atuação é indispensável no processo de formação continuada dos educadores, pois ela é a agência formadora, por 
natureza, dos novos profissionais que irão atuar nas escolas e no processo de acompanhamento da implementação das propostas curriculares.

Finalizando, é importante considerar que uma boa proposta curricular, embora seja condição necessária para construir uma escola de qualidade, não é condição suficiente.

Outras condições concretas e concomitantes à reorientação curricular são fundamentais, como um amplo programa de formação de professores e gestores, o acompanhamento e apoio ao trabalho das escolas, por parte dos órgãos centrais e intermediários das secretarias de educação e a melhoria substantiva nas condições de trabalho e de remuneração docente. Sem essas condições, nenhuma proposta curricular, sozinha, garante a qualidade de ensino nas escolas públicas. 


\section{Curricular decisions and participation}

Abstract: Schools fulfill their social function through curriculum, namely, the set of knowledges and learning experiences offered to students that includes contents to be contemplated and the way they are developed. This article approaches possible participation areas in organized society, particularly by those involved with public education, in curricular decision-making outside or within school space. It points out two logics teaching systems use for curriculum-building: the classic one, more frequent, which moves from the center to the bases; and the participative one, on the opposite sense, from the bases to the center. It underscores the political and pedagogical importance of choosing the second logic, particularly in this moment of Brazilian history when quality public education is part of the agenda, which implies a discussion on curriculum.

Keywords: Curriculum. Curricular decisions. Curriculum and participation. 
APPLE, Michael W. Política cultural e educação. São Paulo: Cortez, 2001.

BORGES, Edna. O currículo e a conjuntura nacional: com a palavra o MEC. In: CENPEC; FUNDAÇÃO ITAÚ SOCIAL (Orgs.). Currículo, construção e participação. São Paulo: Cenpec; Fundação Itaú Social, 2010, p. 15-18.

CHIEFFI, Meyri Venci; REGINATO, Maria José; VIEIRA, Adriano. Uma reorientação curricular em três movimentos. In: CENPEC; FUNDAÇÃO ITAÚ SOCIAL (Orgs.). Currículo, construção e participação. São Paulo: Cenpec; Fundação Itaú Social, 2010, p. 54-93.

FREIRE, Paulo. Pedagogia da autonomia. Rio de Janeiro: Paz e Terra, 1997.

OLIVEIRA, Eliane Carolina. Um diálogo entre a universidade e a rede pública de ensino. In: GOVERNO DO ESTADO DE GOIÁS. SECRETARIA DE ESTADO DA EDUCAÇÃO. Currículo em Debate: Sequências Didáticas: Convite à ação. 6.8.1: Línguas Estrangeiras. Goiânia: Governo do Estado de Goiás, 2009. p. 9.

SACRISTÁN, José Gimeno; PÉREZ GÓMEZ, Angel. Compreender e transformar o ensino. Porto Alegre: Artmed, 2007.

SAMPAIO, Maria das Mercês Ferreira. A escola e duas decisões curriculares. Reflexões sobre o desafio da qualidade do ensino: subsídios para a reorientação curricular. In: Ensinar e aprender: reflexão e criação. São Paulo: Cenpec, 1998, v. 1, p. 12-18.

; GALLIAN, Cláudia Valentina Assumpção. Currículo na escola: uma questão complexa. In: MARIN, Alda Junqueira (Org.). Escolas, organizações e ensino. Araraquara: Junqueira Martins Editores, 2013, p. 169-217.

SAUL, Ana Maria. A participação deve ser uma qualidade na construção do currículo. In: CENPEC; FUNDAÇÃO ITAÚ SOCIAL (Orgs.). Currículo, construção e participação. São Paulo: Cenpec; Fundação Itaú Social, 2010, p. 34-37.

SILVA, Jeymes Martins. Sequência didática 6ำ ano. In: GOVERNO DO ESTADO DE GOIÁS. SECRETARIA DE ESTADO DA EDUCAÇÃO. Currículo em Debate: Sequências Didáticas: Convite à ação: 6.9: Língua Portuguesa. Goiânia: Governo do Estado de Goiás, 2009. p. 49-65.

RECEBIDO: Março de 2014.

APROVADO: Abril de 2014. 